\title{
KRITI - the vegetation of Crete database
}

\section{Erwin Bergmeier}

\begin{abstract}
The TURBOVEG database on the Cretan covers the South Aegean island of Crete including surrounding islands. It contains plot data on all kinds of woody and non-woody vascular plant vegetation. Bryophytes are included in exceptional cases. It includes relevés from all available sources but chiefly own unpublished relevés. The database provides information on about $90 \%$ of the regional flora and of more than 100 endemics. KRITI (GIVD ID EU-GR-001) is a database to be continued. Publications dealing with selected vegetation types or areas have been published.
\end{abstract}

Keywords: Aegean; Greece; Mediterranean vegetation.

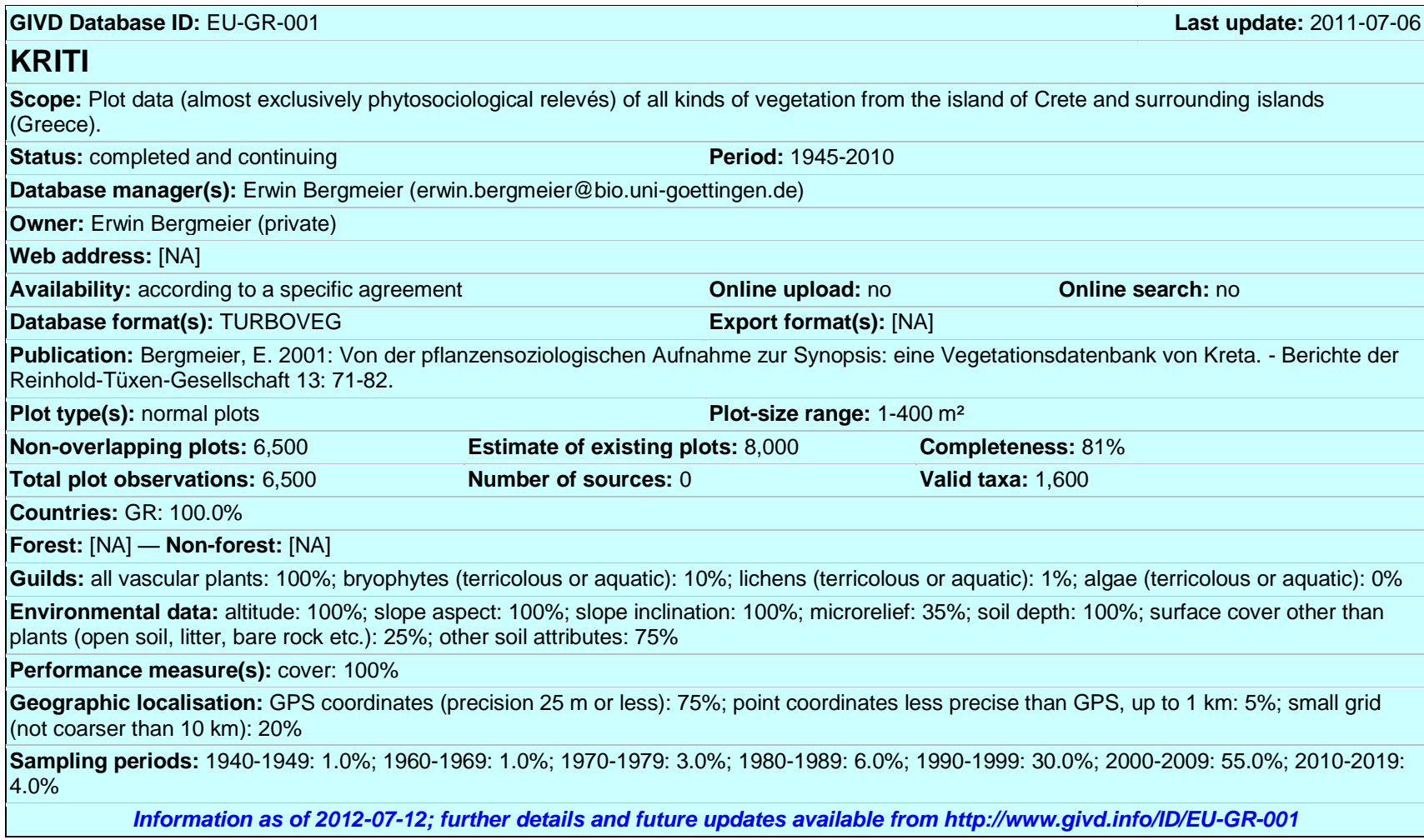

Erwin Bergmeier (erwin.bergmeier@bio.uni-goettingen.de)

Vegetation Analysis \& Phytodiversity, University of Göttingen, Untere Karspüle 2, 37073 Göttingen, GERMANY 